\title{
Clinical implications of novel activating EGFR mutations in malignant peritoneal mesothelioma
}

\author{
Jason M Foster ${ }^{1,4^{*}}$, Uppala Radhakrishna', Venkatesh Govindarajan ${ }^{1}$, Joseph H Carreau ${ }^{1}$, Zoran Gatalica \\ Poonam Sharma², Swapan K Nath ${ }^{3}$, Brian W Loggie ${ }^{1}$
}

\begin{abstract}
Background: There is a paucity of information about the molecular perturbations involved in MPM tumor formation. We previously reported that EGFR-TK mutations in MPM were predictive of achieving optimal surgical cytoreduction, but the status of EGFR pathway activation potential of these mutations was not known. Here we present the mutant EGFR activating potential and the matured survival data of the EGFR mutant(mut+) relative to wild type EGFR(mut-) mesothelioma.

Methods: Twenty-nine patients were evaluated and their tumors were probed for mutations in the catalytic TKdomain. Twenty-five patients were treated with cytoreductive surgery and complete clinical data was available for comparison of the mut+ and mut- groups. A COS-7 cell expression model was used to determine mutation activating profiles and response to erlotinib.
\end{abstract}

Results: Functional mutations were found in 31\%(9/29) of patients; 7 of these mutations were novel and another was the L858R mutation. All missense mutations were found to be activating mutations and responsive to erlotinib. Of the 25 patients managed surgically, there were 7 mut+ and 18 mut-. Two of 7 (29\%) mut+ developed progressive disease and died with a median follow-up time of 22 months; while 13/18 (72\%) mut- developed progressive disease and 10/18 (56\%) died with median TTP of 12 months and median survival of 14 months.

Conclusions: The novel EGFR mutations identified are activating mutations responsive to erlotinib. The mut+ subset have a 'relative' improved outcome. Erlotinib may have a role in MPM and exploration for mutations in a larger patient cohort is warranted.

\section{Introduction}

Discovering the molecular pathways and mutations active in cancer has resulted in the emergence of novel therapies, as well as, the development of objective predictors of clinical outcome and response to cancer therapies. Perturbations and mutations in the epidermal growth factor receptor gene family have been identified in many cancer subtypes with gain of function alterations occurring at all levels of gene and protein expression [1-4]. Recent studies in non small cell lung cancer (NSCLC) have revealed that mutations in epidermal growth factor receptor (EGFR) occur in $15 \%$ of Caucasians and $30 \%$ of Asians with NSCLC, and the presence of specific EGFR mutations is predictive of response to

\footnotetext{
* Correspondence: jfosterm@unmc.edu

'Department of Surgery, Creighton Cancer Center, Creighton University,

Omaha, NE, USA

Full list of author information is available at the end of the article
}

therapy and cancer outcome [5-8]. The reported mutations in NSCLC are deletion or missense mutations that occur between exons 18-24 in the tyrosine kinase domain of the receptor. Investigation of EGFR mutations in lung cancers has become a pivotal research paradigm that has begun to unlock the utility of mutations in predicting clinical outcomes, selection of patients for therapies (EGFR-TKIs), and predicting response/resistance to these therapies.

Recapitulation of EGFR mutations in lung cancer cells in vitro have demonstrated that it is an example of an 'oncogenic addiction' mutation which provides a biologic explanation for the improved outcome seen in this EGFR mutant NSCLC group relative to the wild type group [9]. EGFR mutations are likely not limited to lung cancer and pervasive in other cancer. A potential cancer type similar to NSCLC that might harbor functional EGFR mutations is malignant mesothelioma. The first 
feature common to both malignancies is that EGFR expression is quite common in malignant mesothelioma [10-12]. Also malignant mesothelioma, like NSCLC, is a highly lethal cancer that can arise de novo in the pleural cavity; but unlike NSCLC, mesothelioma can also originate in the peritoneal cavity and soft tissue. Malignant peritoneal mesothelioma (MPM), like pleural mesothelioma, is quite aggressive, with most patients succumbing to this disease within 7-14 months after diagnosis [13]. Treatment of MPM with systemic chemotherapy, radiation, and/or palliative surgery has largely been unsuccessful in improving outcome or extending survival. However, over the last two decades, many groups have shown that aggressive surgical cytoreduction consolidated with intraperitoneal hyperthermic chemotherapy (CRS/IPHC) can improve improved patient outcome in a subset of patients. CRS/IPHC has been the only treatment modality that has yielded long-term survival and cure in selected patients [10,14-19]. At our institution, we perform a high volume of CRS/IPHC for all forms of peritoneal surface malignancies. Through this experience it is evident that many mesothelioma patients do not experience the long term benefits of this aggressive surgical intervention, but all must endure the associated morbidity and mortality. Therefore, identification of surrogate markers that can predict response to CRS/IPHC and lead to novel therapeutic targets in mesothelioma prompted the pursuit of EGFR mutations. We have previously reported that EGFR mutations occur in $31 \%$ of MPM, a rate similar to that reported in NSCLC [20]. When mutations were present they correlated with optimal surgical resection in $100 \%$ of the patients. Since most patients who present with MPM are unresectable, achieving optimal resection is important because it represents the only reproducible (surrogate) factor that predicts long-term survival [14]. Here we report the first identification of EGFR activating mutations in mesothelioma, as well as, the updated clinical outcome.

\section{Materials and methods Patient population}

Twenty-nine consecutive cases of newly diagnosed malignant peritoneal mesothelioma evaluated at Creighton University Medical Center from January 1, 2003 to July 31, 2006 were reviewed. All cases had paraffin embedded tissue available to perform immunostaining and mutation analysis. Institutional review board approval was obtained for this investigation.

\section{Mutation analysis of EGFR in malignant mesothelioma}

Tumor tissues were procured from patients who had undergone surgical resection at the department of surgery, Creighton University Medical Center, Omaha, from January 2003 to July 2006. Twenty-nine formalinfixed paraffin-embedded tissues were available for the analysis. All patients had pathologically proven MPM. The study was approved by the institutional review board of the Creighton University Medical Center. Medical records and hematoxylin and eosin-stained slides of the specimen were reviewed by two pathologists. Tumor tissue with a tumor cell content of greater than 30-40\% was chosen for the analysis. In several cases, tissue sections were microdissected manually to obtain both tumor and histologically normal tissue.

Genomic DNA was isolated from tumors embedded in paraffin blocks using Puregene DNA Purification kits (Gentra systems ${ }^{\circ}$ MN, USA) according to manufacturer's protocol. The EGFR gene (Epidermal growth factor receptor, EGFR; MIM 131550), (Ensembl Gene ID ENSG00000146648) has a total of 28 exons. Genomic DNA were PCR-amplified for 7 different genomic regions of EGFR (Exon 18-24) covering the entire coding sequence of the tyrosine kinase domain and all associated splice junctions. Amplified PCR products were first screened by DHPLC heteroduplex analysis using the Transgenomic WAVE ${ }^{\circ}$ system (Transgenomic, Omaha, NE) as previously described. Samples with variant DHPLC profiles were purified with QIAquick spin columns and sequenced directly (BigDye ${ }^{\circ}$ Terminators sequencing kit, Foster City, CA) in both directions using an automated ABI 3100 genetic analysis system and analyzed using the Sequencer 4.1 software program package (Gene Codes ${ }^{\circ}$, Ann Arbor, MI). Mutant alleles were also cloned by use of the original TA cloning kit (Invitrogen Carlsbad, CA) according to manufacturer's protocol, after PCR amplification, purified and subjected to nucleotide sequencing.

\section{Functional Analyses of Mutant EGFRs}

Full length wild-type EGFR cDNA (Gene bank accession No. NM_005228) were cloned into pIRES-hrGFP-2a expression vector (Stratagene ${ }^{\circ}$ La Jolla, CA). Mutations (W731L, E734Q, T785A, C797Y, Y801H, L831H, L858R and E868G) were introduced into full-length EGFR coding sequence by using a QuikChange II XL Site-Directed Mutagenesis kit (Stratagene). All mutant clones were sequenced to ensure that no additional mutations were introduced. The COS-7 cell line was obtained from American Type Culture Collection (ATCC Manassas, $\mathrm{VA}$ ) and grown in DMEM with high glucose, 10\% FCS, 2 $\mathrm{mM}$ L-glutamine $\left(\mathrm{GIBCO}^{\circ}\right.$ Carlsbad, CA), 10 units $/ \mathrm{ml}$ penicillin, and $10 \mu \mathrm{g} / \mathrm{ml}$ streptomycin. Cells were transfected (Lipofectamine LXT, Invitrogen) using one tube protocol. Briefly, $12.5 \mu \mathrm{g}$ of the expression constructs were mixed thoroughly with $2.5 \mathrm{ml}$ of Opti-MEM I reduced serum medium (Invitrogen) and incubated for 30 minutes at room temperature. DNA-Lipofectamine complexes 
were then added to $8 \mathrm{ml}$ of Opti-MEM I reduced serum medium then plated equal volume in five p60 tissue culture dishes (Falcon ${ }^{\circ}$ San Jose, CA) and incubated at $37^{\circ} \mathrm{C}$ and $5 \% \mathrm{CO}_{2}$. Six hours after the transfection, $2 \mathrm{ml}$ of DMEM with high glucose, $20 \%$ FCS was added to each dish. The next day, cells were switched to reduced serum medium and incubated overnight with $10 \mathrm{ng}$ of EGF per milliliter (Sigma ${ }^{\circ}$ St. Louis, MO). To evaluate the in vitro responsiveness of mutant receptors to EGFR inhibitor, cells were treated with various concentrations of Erlotinib
(Tarceva ${ }^{\circ}$ LC laboratories, Woburn, MA) three hours before the addition of $10 \mathrm{ng}$ of EGF per milliliter. The Stock solutions of Erlotinib were prepared in DMSO and prior to use, diluted in fresh DMEM media. Three independent experiments were performed for all analyses. Cells were exposed to EGF for 15 minutes. The protein preparation and Western blot analysis was performed following the methods described previously.

Equal amounts of protein were prepared in $50 \mu \mathrm{l}$ of Laemmli loading buffer and resolved using 4-15\%

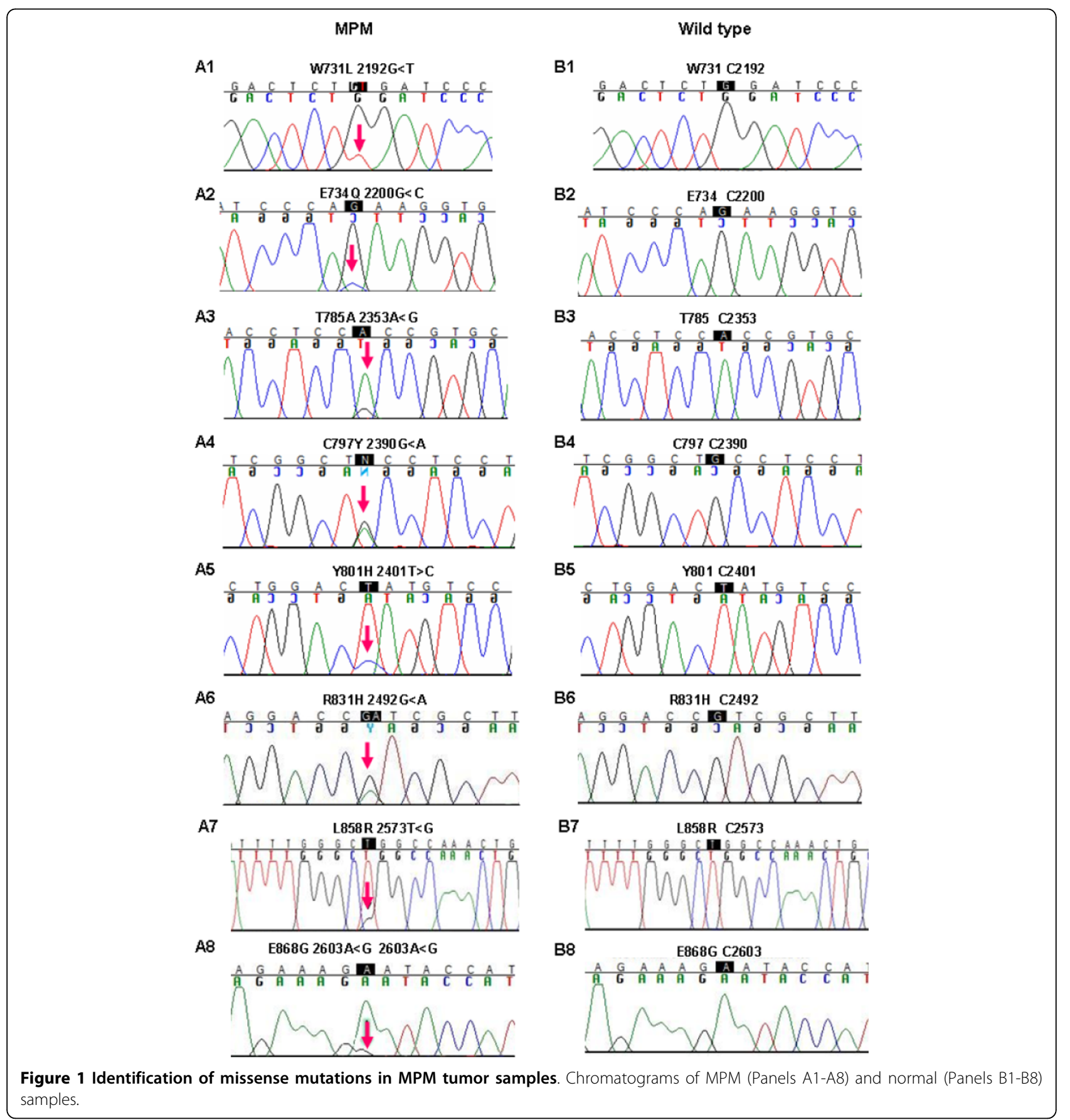


criterion precast Tris-HCL gel electrophoresis (Bio$\operatorname{Rad}^{\oplus}$ Hercules, CA), transferred to nitrocellulose membranes. The efficiency of transfer and uniformity of loading were determined by Ponceau S (Sigma) staining. Western blot analysis was performed with the use of either super signal West femto maximum sensitivity substrate and/or West pico chemiluminescent substrate reagents (Thermo scientific ${ }^{\circledR}$ Rockford, IL). Nitrocellulose membranes were incubated overnight and probed with anti-phospho-EGFR (Cell Signaling Technology ${ }^{\oplus}$, Danvers, MA), and EGFR antibody (Cell Signaling Technology). The densities of specific protein

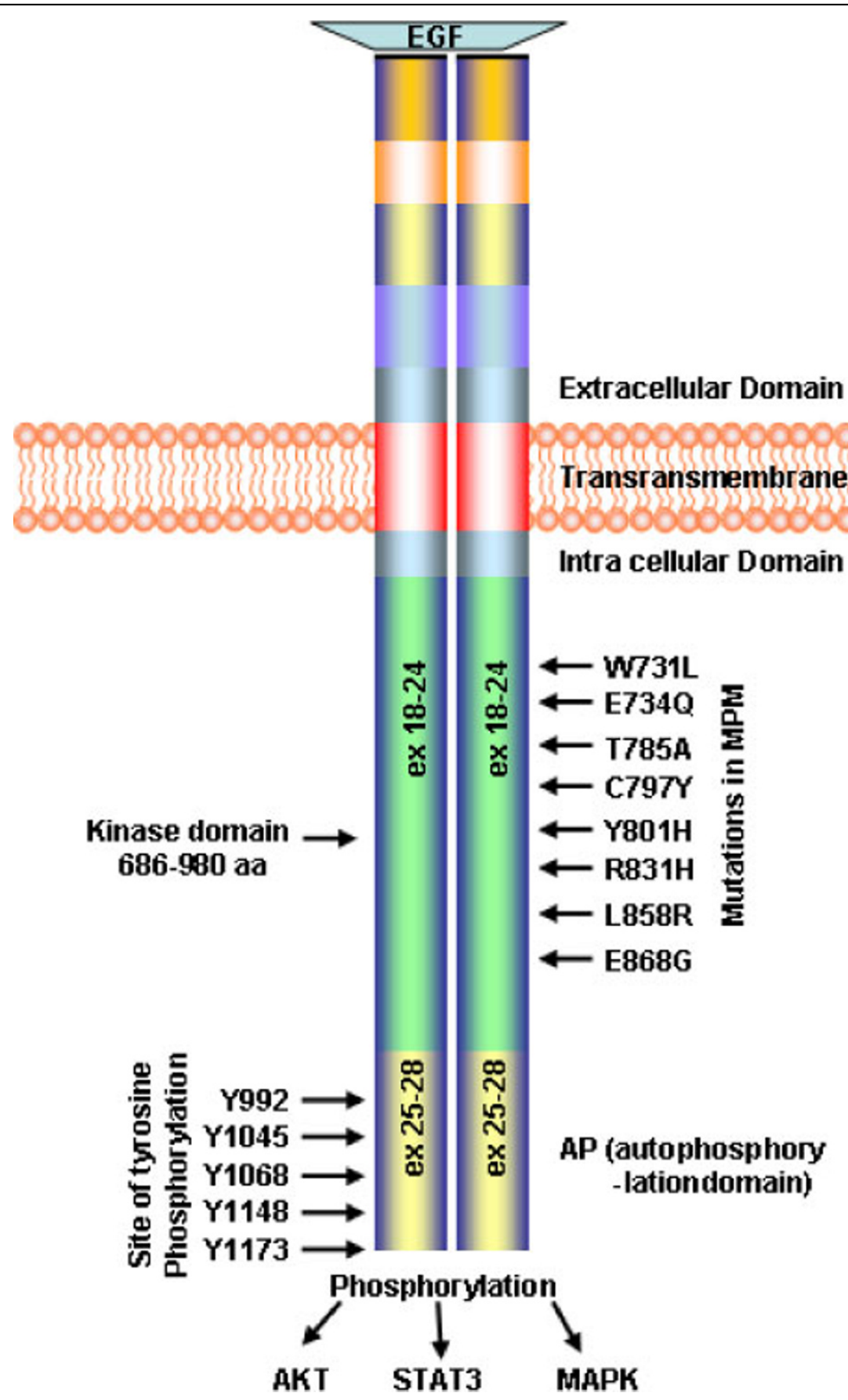

Figure 2 Schematic representation of EGFR protein with the intracellular, transmembrane, extracellular and the TK domains. The known phosphorylation sites (residues numbered) are marked on the left side. Mutations found in MPM samples are marked on the right. Numbers within bars are exons. 
bands were analyzed by densitometry (Quantity One GS-800 Imaging Densitometer, Bio-Rad ${ }^{\oplus}$.

\section{Survival and time to progression analysis}

The statistical analyses were performed in an exploratory manner on twenty-five patients who underwent surgical exploration for cytoreductive surgery and intraperitoneal hyperthermic chemotherapy. When IPHC was performed, patients received either $30-40 \mathrm{mg}$ of Mitomycin C or $800 \mathrm{mg} / \mathrm{M} 2$ of Carboplatin at an inflow temperature of $40.5-42^{\circ} \mathrm{C}$ for $90-120$ minutes. The level of cytoreduction was scored as R1 - no visible disease, $\mathrm{R} 2 \mathrm{a}$ - residual tumor nodules $\leq 5 \mathrm{~mm}, \mathrm{R} 2 \mathrm{~b}$ - residual tumor nodules $>5 \mathrm{~mm} \leq 2 \mathrm{~cm}, \mathrm{R} 2 \mathrm{c}>2 \mathrm{~cm}$, and R3unresectable. Optimal resectability was defined as an R1 or R2a resection. To determine the impact of the presence of mutation on survival and time to progression, a log rank analysis was performed.

\section{Results}

\section{Mutation analysis}

We analyzed a cohort of MPM samples $(\mathrm{n}=29)$ by DHPLC and sequencing analysis, and identified eight mutations in the tyrosine kinase domain (TKD) of EGFR. Of the 8 mutations in the TK domain, 7 were novel (W731L, E734Q, T785A, C797Y, Y801H, L831H and E868G) (Figure 1A, B). One of the mutations (L858R) was previously identified in non-small cell lung cancer (NSCLC) patients and this mutation was found to increase sensitivity to EGFR inhibitor, Erlotinib. All mutations were determined to be somatic, since they were not identified in the analysis of normal tissue from the same patients. Each mutation was only observed once in this cohort, except $\mathrm{L} 831 \mathrm{H}$ which was detected in two independent tumors. In addition, analysis of 100 unrelated normal controls from the same ethnic origin did not identify these variants indicating that these are most likely not rare polymorphisms. No mutations were identified within the kinase domain of ERBB2 in this MPM sample set.
EGFR and ERBB2 copy number status was assessed using FISH and quantitative PCR, and no evidence of amplification of either gene was found in all specimens (data not shown). Expression of the EGFR alternative transcript variant, EGFRvIII, could not be detected by RT-PCR (data not shown).

All the mutations were in the TK domain that is critical for EGFR activity (Figure 2). Sequence alignment of the human wild- type EGFR with the Pfam model of protein kinase domain indicates W731, E734, T785, C797, Y801, R831, L858 and E868 that the mutations were in highly conserved residues (Figure 3).

\section{Time-response studies of EGFR on MM mutations in COS} 7 cells

The functional properties of the EGFR mutations were tested by transient transfection assays. The eight mutations were first introduced into the wild type human EGFR by site directed mutagenesis. The mutant EGFRs were then transfected into COS-7 cells and exposed to $E G F$. Total proteins isolated from these cells were resolved by SDS-PAGE, blotted and probed with antiphospho EGFR (Y1068) and anti-EGFR antibodies. EGFR activation was assayed by quantification of tyrosine 1068 (Y1068) residue, commonly used as a marker of autophosphorylation of EGFR. All mutant EGFRs showed enhanced phosphorylation in a time-dependent manner, with a maximal response at 15 minutes. All the 8 mutations showed a similar activation profile (Figure 4, 5). These results demonstrated that the mutations were activating.

\section{Dose response studies of Erlotinib on COS-7 transfected cells}

In order to investigate whether the EGFR mutations are sensitive to the EGFR inhibitor Erlotinib, COS-7 cells transfected with mutant EGFR and treated with various concentrations $(0.002$ to $2.0 \mu \mathrm{M})$ of Erlotinib and exposed to EGF. EGFR phosphorylation was significantly decreased in a dose-dependent manner for all eight

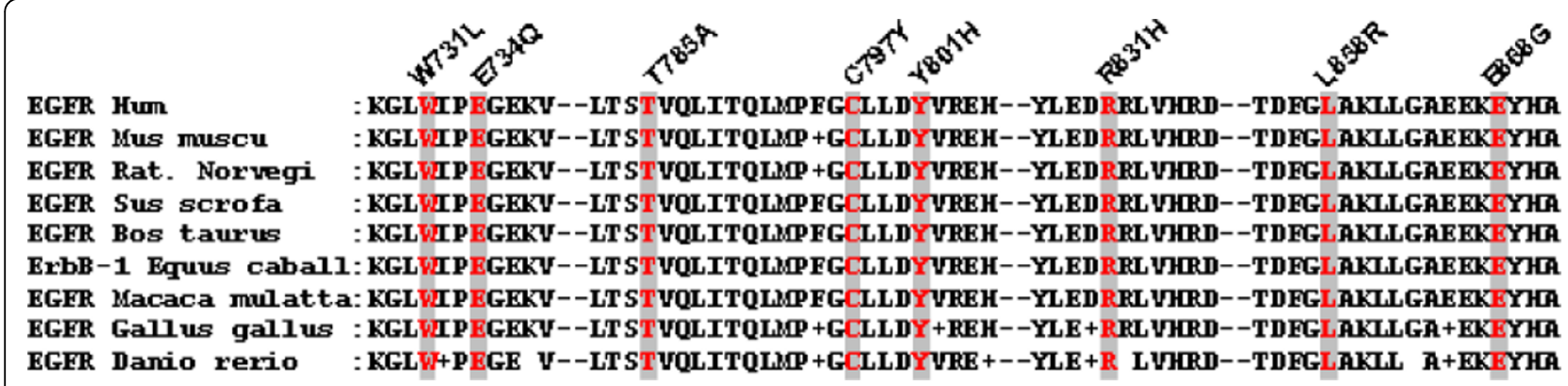

Figure 3 Amino acid sequence comparisons of EGFR-TK domain from members of the EGFR family of proteins from different species. The amino acids at position W731, E734, T785, C797, Y801, R831, L858 and E868 were conserved in several species. 


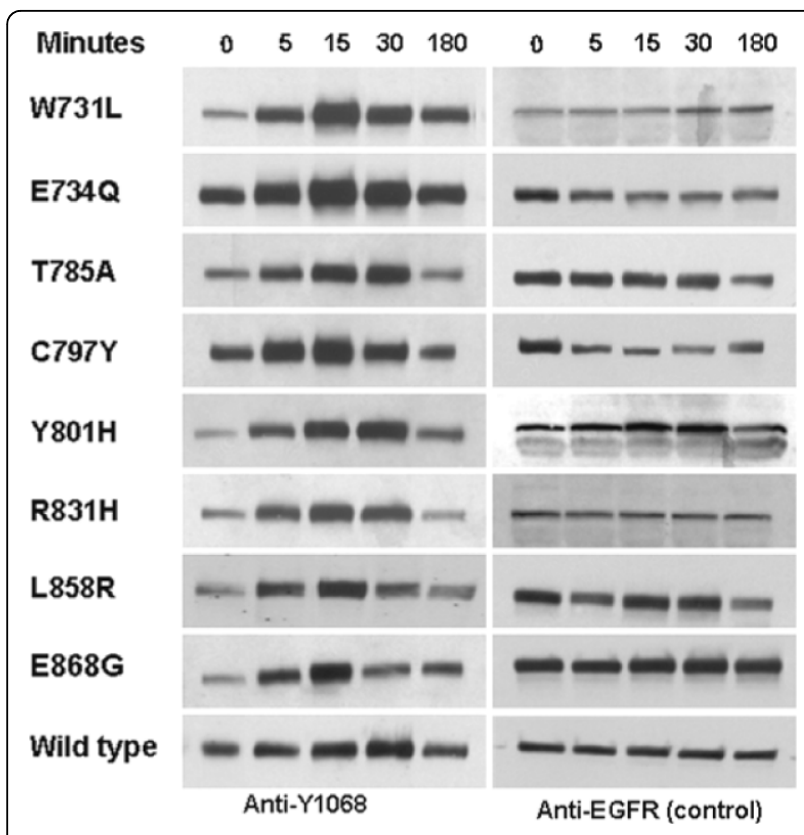

Figure 4 EGFR mutations from MPM tumor samples are activating mutations. Western blot analysis of phosphorylated EGFR and total EGFR from transfectants expressing EGFR mutations.

mutants, with a minimum response at $.002 \mu \mathrm{M}$, a maximal response at $2.0 \mathrm{mM}$ (Figure 6, 7).

\section{Impact of EGFR mutations on survival and time to} progression (TTP)

Twenty-five of the 29 patients were treated with surgical cytoreduction and intraperitoneal hyperthermic therapy with median follow-up time of 24 months. Eight patients had tumors with mutant EGFR while

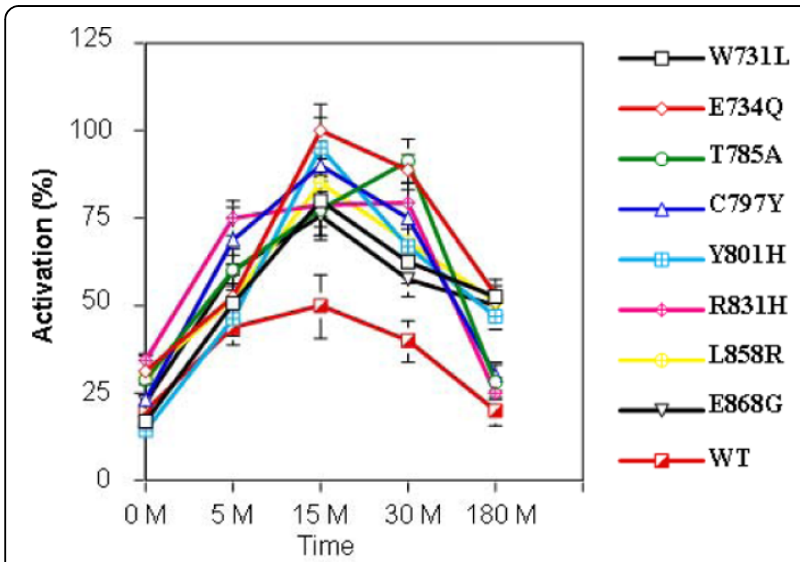

Figure 5 Quantitative analysis of EGFR phosphorylation in COS-7 cell transfectants expressing mutant EGFR.

Autoradiographs of three independent experiments were quantified. The intensity of EGFR phosphorylation has been adjusted for total EGFR expression. Error bars denote standard deviation.

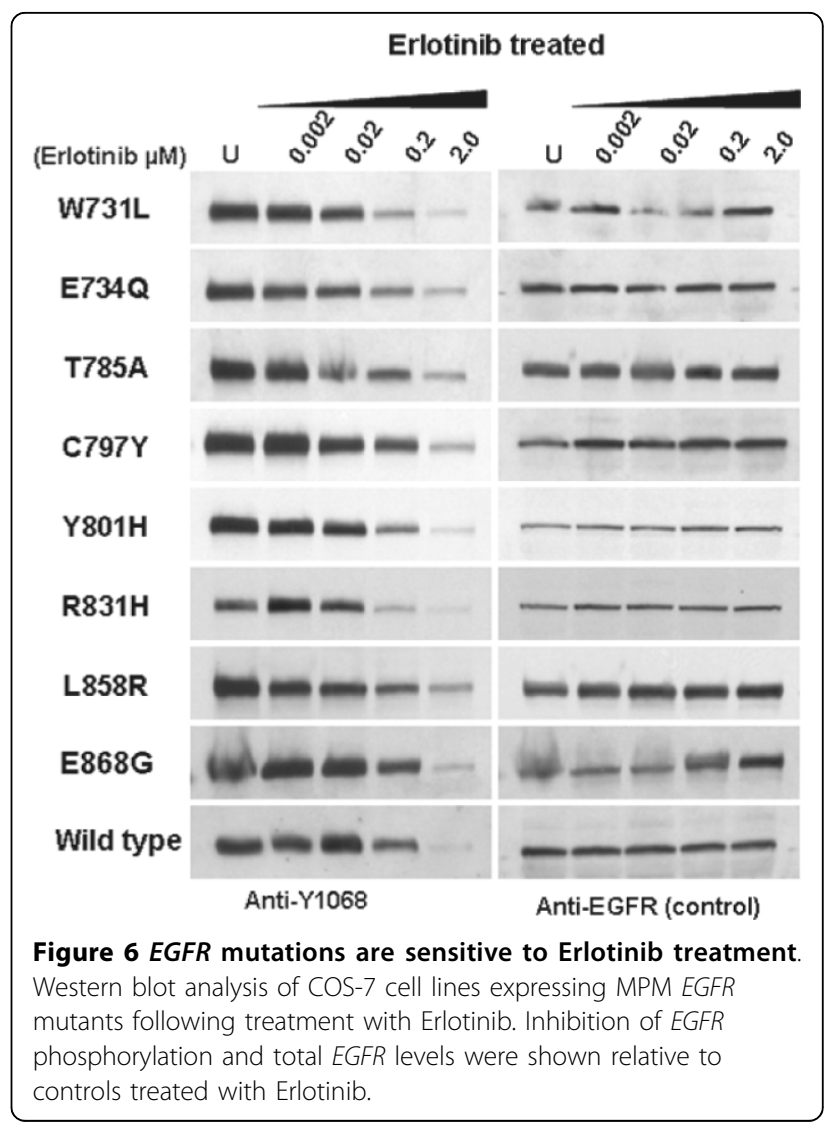

the other 17 patients had wild type EGFR. In the EGFR mutant patients, median survival has not been reached but $29 \%(2 / 7)$ of patients have died due to disease progression with a median follow-up time of 22 months; while $56 \%(10 / 18)$ of wild type patients have

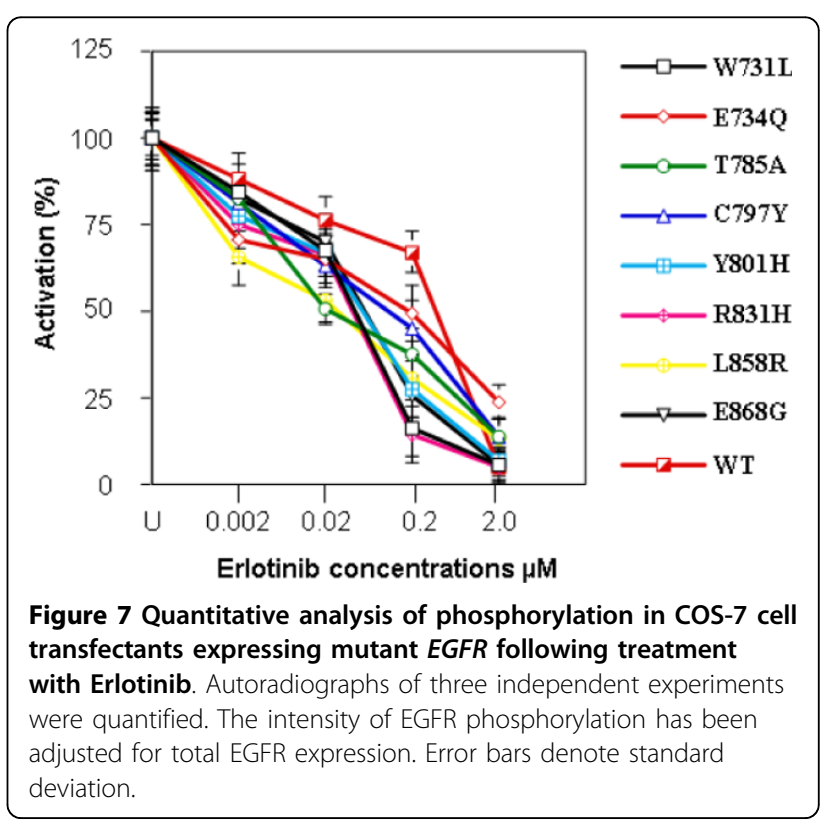



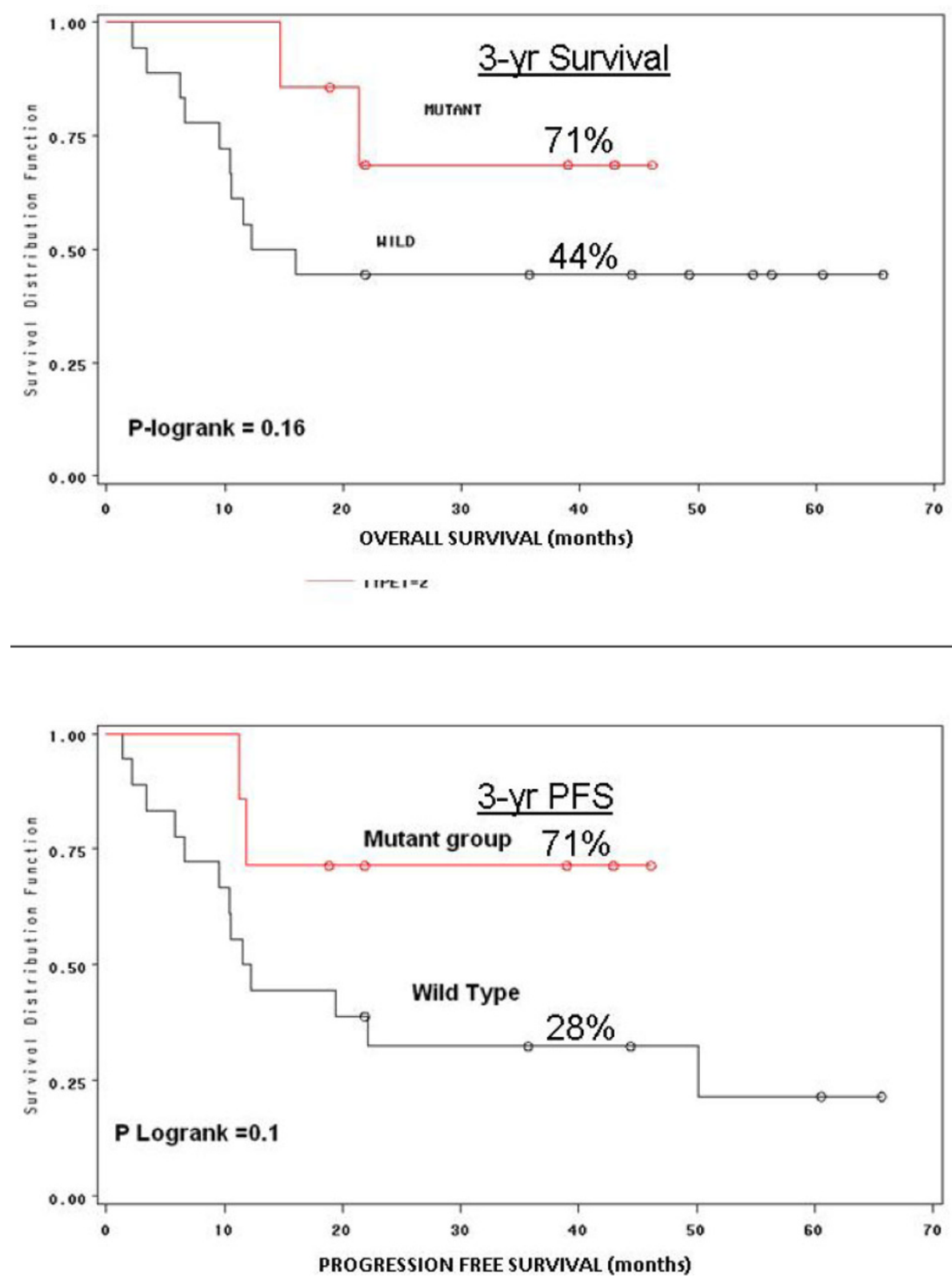

Figure 8 (A) Log rank analysis of death due to disease and (B) progression free survival based on the presence of a functional EGFR mutation.

died due to disease progression with a median survival of 14 months. The time to progression in the wild type group is 12 months with $72 \%$ (13/18) of patients developing progressive disease. However, only $29 \%(2 / 7)$ of EGFR mutant patients have developed progressive disease and median TTP has not been reached. Log rank analysis revealed that 3 -year OS and DFS was $71 \%$ and $71 \%$ for the mutant group; $44 \%$ and $21 \%$ for the wild type group (Figure 8A, B).

\section{Discussion}

We have identified seven novel and one known point mutations in the EGFR-TK domain in MPM patients. All mutations are clustered and reside near the ATPbinding cleft of the tyrosine kinase domain. Presence of each mutation in heterozygous condition indicates that these mutant proteins with intact domains may influence wild-type protein expressed from the non-affected allele and/or other EGFR factors in a dominant-negative 

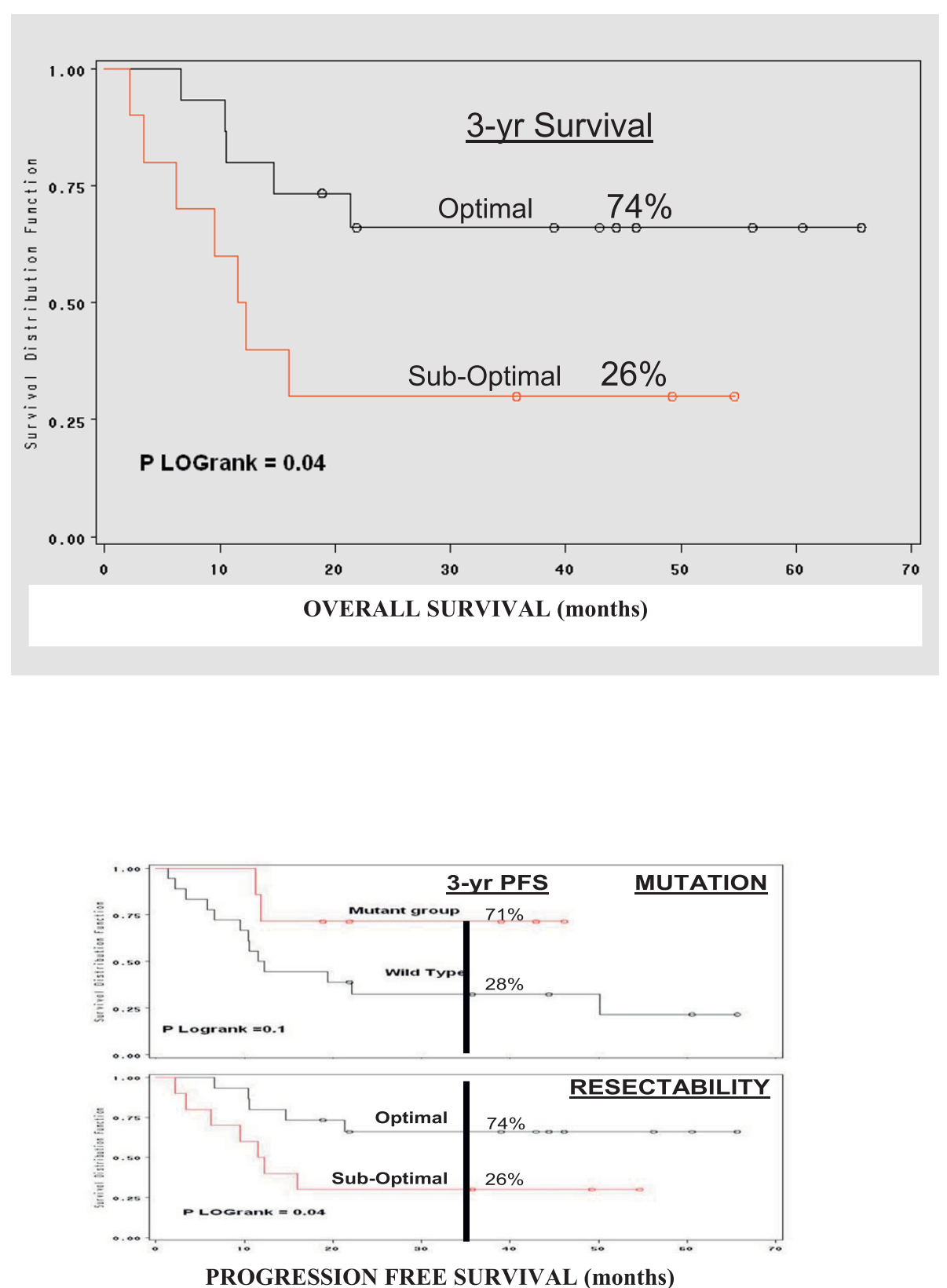

Figure 9 (A) Log rank analysis of death due to disease base on cytoreduction score (optimal vs. sub-optimal, previously published in Annals Surg Oncology 2009 Jan: 16(1) 152-8); (B) Superimposed log rank analysis of death due to disease base on cytoreduction score and PFS based on mutation.

manner by the occupation of their binding sites through mutant EGFR proteins. These mutation add to the list of previously identified mutations within the kinase domain of the EGFR gene, and also extends the spectrum of malignancies that harbor functional EGFR mutations. To our knowledge, this is the first report identifying functional EGFR mutations in malignant mesothelioma.
Functional analyses of these mutant EGFRs in the cultured cells demonstrated that all EGFR mutants have enhanced tyrosine kinase activity in response to epidermal growth factor and increased sensitivity to EGFR inhibitor Erlotinib. Like other mutants reported in the literature, all eight EGFR mutants were ligand dependent and in the absence of EGF stimulation there was little or no activation of any mutant EGFR. These results 
confirm previous observations showing activation of TKD mutant EGFR as being ligand dependent in similar transient expression systems (NIH3T3 and HeLa cells), while there was no evidence of significant ligand independent EGFR activation.

Clinically, the presence of EGFR mutations in MPM appears to predict response to therapy (CRS/IPHC) and represents a potential predictor of improved outcome compared to the wild type MPM. We have previously reported that presence of EGFR mutation(s) in MPM is predictive of optimal resectability, the only reproducible surrogate marker for long term survival with this disease [14]. While resectability is useful, it does not circumvent the associated risks of CRS/IPHC and often cannot be determined preoperatively given the miliary nature of this disease. In figure 9A the optimal resected patients have a statistically significant survival benefit relative to sub-optimal group and a similar outcome was observed in the mutant EGFR patients relative to wild type EGFR group (Figure 9B). In the 13/18 wild type patients that developed progressive disease 10 have died and 3 are currently enrolled in hospice with comfort care measures.

The impact of EGFR mutations in MPM strikingly parallels the observation reported in NSCLC. Specifically the finding that EGFR mutations are predictive of response to therapy [5-8,21-25]. In lung cancer this has been demonstrated in the context of systemic chemotherapy and/or EGFR-TK therapy. In this study, treatment is cytoreductive surgery with intraperitoneal hyperthermic chemotherapy. The finding that EGFR mutations identify responders to therapy mechanistically is explained at the cellular/molecular by the 'oncogenic addition (shock)' model [9,26-28]. In this model, cancers that are dependent on critical oncogenic pathways, like the EGFR pathway for tumor cellular maintenance, undergo an exaggerated/prolonged apoptosis relative to wild type tumor cells when exposed to the same cytotoxic agents [9]. The improved outcome in EGFR MPM mutants is also supported by this model. First, all gross disease is removed surgically, leaving only microscopic to low volume residual disease. This residual disease subsequently is treated with high dose intra-peritoneal chemotherapy and hyperthermia given intra-operatively, and the intrinsic susceptibility of EGFR MPM mutant tumors makes these cells more likely to undergo more extensive apoptosis which manifests as a prolonged progression free survival (Figure 9B).

Although the mutant EGFR group experienced a prolonged survival, two patients in this group have succumbed to their disease, and likely with longer follow-up, more mutant EGFR patients will develop progressive disease. Therefore, the improved outcome observed in the mutant EGFR group is a 'relative' phenomenon.
This 'relative' outcome improvement in mutant MPM patients also parallels the observations in metastatic lung cancer which report prolonged median survival but ultimately most patients, including EGFR mutants succumb to progressive diseases. Since NSCLC clinically are responsive to TKI therapy and given the in vitro response of the MPM mutations to Erlotinib, there may be a role for EGFR-TKI therapy in MPM EGFR mutant patients who develop disease recurrence or present with bulky unresectable tumor. Currently EGFR-TKI therapy has not been investigated in peritoneal mesothelioma but a recent trial in pleural mesothelioma did not show any benefit [29]. Interestingly in this erlotinib trial, the high EGFR expressing tumor group experienced a 2-fold longer survival, but study did not interrogate tumors for EGFR mutations. Therefore it is unknown if EGFR mutations occur in pleural mesothelioma or if a subset of mesothelioma patients might benefit from EGFR-TKI therapy and further investigation for perturbations in the EGFR pathway in pleural mesothelioma is warranted.

In summary, we have identified novel activating EGFR mutations in MPM associated with optimal resectability and prolonged survival. Clinically these mutations may ultimately have utility in patient selection for surgery, systemic therapy, and selection for EGFR-TKI. The identification of EGFR mutations in peritoneal mesothelioma expands the spectrum of cancers with EGFR pathway perturbations and provides the first evidence of function EGFR mutations in mesothelioma. Not only does the 'in vitro' biological behavior of these mutations parallel those identified in NSCLC, but the clinical course of MPM patients with EGFR mutant tumors appear to share same 'relative' improved clinical outcome like mutant EGFR-NSCLC. Expanding the cohort of peritoneal mesothelioma and probing for mutations in pleural based disease is warranted.

\section{Acknowledgements}

We especially thank Cavenee Webster for the wild-type EGFR CDNA. We thank Boosani C, Akulapalli S from Boys Town Research Hospital, Omaha and Maiti A.K. from University of Texas, Galveston for advice and assistance. The work was supported by Paul and Michelle Zygielbaum Cancer Research Fund and also in part by anonymous donors.

\section{Author details}

'Department of Surgery, Creighton Cancer Center, Creighton University, Omaha, NE, USA. ${ }^{2}$ Department of Pathology, Creighton University Medical Center, 601 N 30th St., Omaha, NE, USA. ${ }^{3}$ Department of Arthritis and Immunology, Oklahoma University, Oklahoma City OK, USA. "Department of Surgery, University of Nebraska Medical Center, Omaha, NE, USA.

\section{Authors' contributions}

JMF participated in study design/conception, clinical data collection/ interpretation, coordination, and project oversight. RU performed the basic science analysis that demonstrated mutation activity. VG participated and coordinated the basic science data. JHC performed the patient data extraction for the outcome analysis and validated clinical outcome data. ZG 
participated in study design, coordination, clinical tissue extraction and analysis resulting in the identification of the EGFR mutations. PS participated in clinical tissue extraction and analysis resulting in the identification of the EGFR mutations. SN performed the statistical analysis. BWL participated in study design, coordination, and oversight. All authors read and approved the final manuscript.

\section{Competing interests}

The authors declare that they have no competing interests.

Received: 3 May 2010 Accepted: 13 October 2010

Published: 13 October 2010

\section{References}

1. Sequist LV, Joshi VA, Janne PA, Bell DW, Fidias P, Lindeman NI, Louis DN, Lee JC, Mark EJ, Longtine J, Verlander P, Kucherlapati R, Meyerson M, Haber DA, Johnson BE, Lynch TJ: Epidermal growth factor receptor mutation testing in the care of lung cancer patients. Clin Cancer Res 2006, 12:4403s-4408s.

2. Kosaka T, Yatabe Y, Endoh H, Kuwano H, Takahashi T, Mitsudomi T: Mutations of the epidermal growth factor receptor gene in lung cancer: biological and clinical implications. Cancer Res 2004, 64:8919-8923.

3. Lee CM, Lee RJ, Hammond E, Tsodikov A, Dodson M, Zempolich K, Gaffney DK: Expression of HER2neu (c-erbB-2) and epidermal growth factor receptor in cervical cancer: prognostic correlation with clinical characteristics, and comparison of manual and automated imaging analysis. Gynecol Oncol 2004, 93:209-214.

4. Riviere A, Becker J, Loning T: Comparative investigation of c-erbB2/neu expression in head and neck tumors and mammary cancer. Cancer 1991, 67:2142-2149.

5. Paez JG, Janne PA, Lee JC, Tracy S, Greulich H, Gabriel S, Herman P, Kaye FJ, Lindeman N, Boggon TJ, Naoki K, Sasaki H, Fujii Y, Eck MJ, Sellers WR, Johnson $B E$, Meyerson M: EGFR mutations in lung cancer: correlation with clinical response to gefitinib therapy. Science 2004, 304:1497-1500.

6. Tsao MS, Sakurada A, Cutz JC, Zhu CQ, Kamel-Reid S, Squire J, Lorimer I, Zhang T, Liu N, Daneshmand M, Marrano P, da Cunha Santos G, Lagarde A, Richardson F, Seymour L, Whitehead M, Ding K, Pater J, Shepherd FA: Erlotinib in lung cancer - molecular and clinical predictors of outcome. N Engl J Med 2005, 353:133-144.

7. Shepherd FA, Rodrigues Pereira J, Ciuleanu T, Tan EH, Hirsh V Thongprasert S, Campos D, Maoleekoonpiroj S, Smylie M, Martins R, van Kooten M, Dediu M, Findlay B, Tu D, Johnston D, Bezjak A, Clark G, Santabarbara P, Seymour L: Erlotinib in previously treated non-small-cell lung cancer. N Engl J Med 2005, 353:123-132.

8. Lynch TJ, Bell DW, Sordella R, Gurubhagavatula S, Okimoto RA, Brannigan BW, Harris PL, Haserlat SM, Supko JG, Haluska FG, Louis DN, Christiani DC, Settleman J, Haber DA: Activating mutations in the epidermal growth factor receptor underlying responsiveness of nonsmall-cell lung cancer to gefitinib. N Engl J Med 2004, 350:2129-2139.

9. Sharma SV, Gajowniczek P, Way IP, Lee DY, Jiang J, Yuza Y, Classon M, Haber DA, Settleman J: A common signaling cascade may underlie "addiction" to the Src, BCR-ABL, and EGF receptor oncogenes. Cancer Cell 2006, 10:425-435.

10. Nonaka D, Kusamura S, Baratti D, Casali P, Cabras AD, Younan R, Rosai J, Deraco M: Diffuse malignant mesothelioma of the peritoneum: a clinicopathological study of 35 patients treated locoregionally at a single institution. Cancer 2005, 104:2181-2188.

11. Trupiano JK, Geisinger KR, Willingham MC, Manders P, Zbieranski N, Case D, Levine EA: Diffuse malignant mesothelioma of the peritoneum and pleura, analysis of markers. Mod Pathol 2004, 17:476-481.

12. Destro A, Ceresoli GL, Falleni M, Zucali PA, Morenghi E, Bianchi P, Pellegrini C, Cordani N, Vaira V, Alloisio M, Rizzi A, Bosari S, Roncalli M: EGFR overexpression in malignant pleural mesothelioma. An immunohistochemical and molecular study with clinico-pathological correlations. Lung Cancer 2006, 51:207-215.

13. Eltabbakh GH, Piver MS, Hempling RE, Recio FO, Intengen ME: Clinical picture, response to therapy, and survival of women with diffuse malignant peritoneal mesothelioma. J Surg Oncol 1999, 70:6-12.

14. Feldman AL, Libutti SK, Pingpank JF, Bartlett DL, Beresnev TH, Mavroukakis SM, Steinberg SM, Liewehr DJ, Kleiner DE, Alexander HR: Analysis of factors associated with outcome in patients with malignant peritoneal mesothelioma undergoing surgical debulking and intraperitoneal chemotherapy. J Clin Oncol 2003, 21:4560-4567.

15. Sugarbaker PH, Acherman YI, Gonzalez-Moreno S, Ortega-Perez G, Stuart OA, Marchettini $P, Y O O$ D: Diagnosis and treatment of peritoneal mesothelioma: The Washington Cancer Institute experience. Semin Oncol 2002, 29:51-61.

16. Deraco M, Nonaka D, Baratti D, Casali P, Rosai J, Younan R, Salvatore A, Cabras Ad AD, Kusamura S: Prognostic analysis of clinicopathologic factors in 49 patients with diffuse malignant peritoneal mesothelioma treated with cytoreductive surgery and intraperitoneal hyperthermic perfusion. Ann Surg Oncol 2006, 13:229-237.

17. Yan TD, Brun EA, Cerruto CA, Haveric N, Chang D, Sugarbaker PH: Prognostic indicators for patients undergoing cytoreductive surgery and perioperative intraperitoneal chemotherapy for diffuse malignant peritoneal mesothelioma. Ann Surg Oncol 2007, 14:41-49.

18. Sebbag G, Yan H, Shmookler BM, Chang D, Sugarbaker PH: Results of treatment of 33 patients with peritoneal mesothelioma. Br J Surg 2000, 87:1587-1593.

19. Park BJ, Alexander HR, Libutti SK, Wu P, Royalty D, Kranda KC, Bartlett DL: Treatment of primary peritoneal mesothelioma by continuous hyperthermic peritoneal perfusion (CHPP). Ann Surg Oncol 1999, 6:582-590.

20. Foster JM, Gatalica Z, Lilleberg S, Haynatzki G, Loggie BW: Novel and existing mutations in the tyrosine kinase domain of the epidermal growth factor receptor are predictors of optimal resectability in malignant peritoneal mesothelioma. Ann Surg Oncol 2009, 16:152-158.

21. Amann J, Kalyankrishna S, Massion PP, Ohm JE, Girard L, Shigematsu H, Peyton M, Juroske D, Huang Y, Stuart Salmon J, Kim YH, Pollack JR, Yanagisawa K, Gazdar A, Minna JD, Kurie JM, Carbone DP: Aberrant epidermal growth factor receptor signaling and enhanced sensitivity to EGFR inhibitors in lung cancer. Cancer Res 2005, 65:226-235.

22. Jackman DM, Yeap BY, Sequist LV, Lindeman N, Holmes AJ, Joshi VA, Bell DW, Huberman MS, Halmos B, Rabin MS, Haber DA, Lynch TJ, Meyerson M, Johnson BE, Janne PA: Exon 19 deletion mutations of epidermal growth factor receptor are associated with prolonged survival in non-small cell lung cancer patients treated with gefitinib or erlotinib. Clin Cancer Res 2006, 12:3908-3914.

23. Han SW, Kim TY, Hwang PG, Jeong S, Kim J, Choi IS, Oh DY, Kim JH, Kim DW, Chung DH, Im SA, Kim YT, Lee JS, Heo DS, Bang YJ, Kim NK: Predictive and prognostic impact of epidermal growth factor receptor mutation in non-small-cell lung cancer patients treated with gefitinib. $J$ Clin Oncol 2005, 23:2493-2501.

24. Mitsudomi T, Kosaka T, Endoh H, Horio Y, Hida T, Mori S, Hatooka S, Shinoda M, Takahashi T, Yatabe Y: Mutations of the epidermal growth factor receptor gene predict prolonged survival after gefitinib treatment in patients with non-small-cell lung cancer with postoperative recurrence. J Clin Oncol 2005, 23:2513-2520.

25. Yang $\mathrm{CH}, \mathrm{Yu} \mathrm{CJ}$, Shih JY, Chang YC, Hu FC, Tsai MC, Chen KY, Lin ZZ, Huang CJ, Shun CT, Huang CL, Bean J, Cheng AL, Pao W, Yang PC: Specific EGFR mutations predict treatment outcome of stage IIIB/IV patients with chemotherapy-naive non-small-cell lung cancer receiving first-line gefitinib monotherapy. J Clin Oncol 2008, 26:2745-2753.

26. Weinstein IB, Begemann M, Zhou P, Han EK, Sgambato A, Doki Y, Arber N, Ciaparrone M, Yamamoto H: Disorders in cell circuitry associated with multistage carcinogenesis: exploitable targets for cancer prevention and therapy. Clin Cancer Res 1997, 3:2696-2702.

27. Weinstein IB: Cancer. Addiction to oncogenes-the Achilles heal of cancer. Science 2002, 297:63-64.

28. Weinstein IB: Disorders in cell circuitry during multistage carcinogenesis: the role of homeostasis. Carcinogenesis 2000, 21:857-864.

29. Govindan R, Kratzke RA, Herndon JE, Niehans GA, Vollmer R, Watson D, Green MR, Kindler HL: Gefitinib in patients with malignant mesothelioma: a phase II study by the Cancer and Leukemia Group B. Clin Cancer Res 2005, 11:2300-2304.

doi:10.1186/1477-7819-8-88

Cite this article as: Foster et al: Clinical implications of novel activating EGFR mutations in malignant peritoneal mesothelioma. World Journal of Surgical Oncology 2010 8:88. 